\title{
Late EEG Responses Are Absent for Conscious But Task-Irrelevant Stimuli
}

\author{
Joaquin Navajas ${ }^{1,2}$ and Lisandro N. Kaunitz ${ }^{3,4}$ \\ ${ }^{1}$ Institute of Cognitive Neuroscience, University College London, London, WC1N 3AR, United Kingdom, ${ }^{2}$ Centre for Systems Neuroscience, University of \\ Leicester, Leicester, LE1 7RH, United Kingdom, ${ }^{3}$ School of Psychological Sciences, Faculty of Biomedical and Psychological Sciences, Monash University, \\ Victoria 3800, Australia, and ${ }^{4}$ Research Center for Advanced Science and Technology, The University of Tokyo, Tokyo, 153-8904, Japan \\ Review of Shafto and Pitts
}

Thousands of neural circuits are activated in our brains each second, but only some of them (quite mysteriously) give rise to conscious perception (Koch, 2004). The neuroscience of consciousness is the quest to identify these processes: a crucial pursuit with a wide range of applications, such as assessing consciousness in comatose patients and animals and restoring conscious sensory functions in braindamaged patients.

A first step toward solving the ambitious problem of explaining consciousness is recognizing the brain regions and the temporal dynamics of neural processes involved in generating conscious perceptions. For this problem, two conflicting views have been proposed. One theory, the global neuronal workspace (Dehaene and Naccache, 2001), suggests that consciousness arises with a global late ignition ( 300-500 ms) across different cortical regions (Dehaene and Changeux, 2011). Another view asserts that recurrent cortical activity at earlier latencies (150$250 \mathrm{~ms}$ ) corresponds more closely to con-

Received 0ct. 3, 2015; revised Nov. 10, 2015; accepted Nov. 16, 2015.

J.N. is supported by the European Research Council StG (NEUROCODEC, \#309865). L.N.K. is supported by a Fellowship from the Japanese Society for the Promotion of Science.

The authors declare no competing financial interests.

Correspondence should be addressed to Joaquin Navajas, Institute of

Cognitive Neuroscience, University College London, 17 Queen Square, London, WC1N3AR. E-mail:j.navajas@ucl.ac.uk.

DOI:10.1523/JNEUROSCI.3645-15.2016

Copyright $\odot 2016$ the authors $\quad 0270-6474 / 16 / 360004-03 \$ 15.00 / 0$ scious perception (Lamme, 2000; Koivisto and Revonsuo, 2010).

To distil the neural processes associated with conscious perception from those present in the absence of awareness, previous research has relied on contrastive analysis (Baars, 1988). This method involves presenting subjects with stimuli that are consciously seen on only some trials (for example, $50 \%$ of the time), and comparing the brain activity associated with each perceptual state ("seen" vs "unseen" conditions). For more than a decade, contrastive analysis has been considered the gold standard in the search for the neural correlates of consciousness (NCCs). Recently, however, several researchers have argued that this method is unable to disentangle conscious from nonconscious neural activity (Aru et al., 2012; de Graaf et al., 2012). One of these criticisms resides in the impossibility of distinguishing NCCs from (1) the neural correlates of the prerequisites for consciousness (pre-NCCs, i.e., the neural events occurring before the NCCs) and (2) the neural correlates of the consequences of consciousness (co-NCCs, the neural events following the NCCs) (Aru et al., 2012; de Graaf et al., 2012). According to this view, "seen" and "unseen" trials might differ in several aspects besides the perceptual state of the subject. For example, the NCCs could be mixed up with the correlates of reporting one's perception (Pitts et al., 2014) after the NCC has taken place (co-NCC) or with the allocation of attentional resources (Lamme,
2003) before the occurrence of the NCC (pre-NCC). These potential confounds have led researchers to ask what the appropriate methods to study conscious perception are (Navajas et al., 2014; Aru and Bachmann, 2015).

Building upon these observations, several studies have tried to disentangle the NCCs from the neural correlates of reporting one's perception, regarded as a co-NCC. The challenge, of course, is to design an experiment in which the experimenter can assess participants' subjective awareness without asking subjects for an explicit report. To meet this challenge, Pitts et al. (2012) adapted the inattentional blindness paradigm to record event-related potentials (ERPs) with scalp electroencephalography (EEG). The main novelty of this experimental design is that it allowed the researchers to identify neural signals modulated by conscious perception independently of whether the content of conscious perception was taskrelevant. To do so, the authors compared the ERPs elicited on a block of trials in which participants reported their perception with those on another set of trials in which subjects were aware of the critical stimuli but were performing a different task (for a detailed review on the experimental design, see Pitts et al., 2014).

In a recent paper, Shafto and Pitts (2015) adapted this paradigm to specifically study the N170, an occipitotemporal component of EEG that was 
previously shown to be associated with conscious face perception (Fisch et al., 2009; Navajas et al., 2013; Sandberg et al., 2013). The goal of the study was to dissociate the neural correlates of conscious face perception from the neural correlates of reporting a face (Shafto and Pitts, 2015). The authors showed that the N170, and a later EEG component peaking at $\sim 250 \mathrm{~ms}$ [known as the visual-awareness negativity (VAN)], correlated with conscious perception independently of the task relevance of the faces. In contrast, a later component, $\mathrm{P} 3 \mathrm{~b}$, was absent when faces were consciously perceived but taskirrelevant. Altogether, their results challenge theoretical accounts predicting a late (>300 ms) emergence of conscious perception (Dehaene et al., 2003). In particular, the results suggest that previous studies could have confounded consciousness with task relevance.

The findings of Shafto and Pitts (2015) add to the evidence against proposals linking late (>300 ms) EEG components with the NCC. For example, P3 components (either $\mathrm{P} 3 \mathrm{a}$ or $\mathrm{P} 3 \mathrm{~b}$ ) are absent in a range of conditions in which participants are aware of stimuli that are irrelevant to their task: when subjects passively observe a sequence of distractor images appearing on the screen (Sutton et al., 1965), and when they actively fixate on distractors during a free eye-movement visual scene exploration (Kaunitz et al., 2014). In both cases, subjects pay attention and consciously recognize those stimuli as distractors as opposed to targets, but the P3 component is absent. Similarly, the P3 component associated with task-relevant stimuli disappears when those stimuli (still consciously perceived) become taskirrelevant (Pitts et al., 2012; Shafto and Pitts, 2015). All this evidence suggests that, in tasks requiring subjects to identify a target that was present in a fraction of trials, the P3 component might reflect task-relevant target detection rather than conscious perception.

One could speculate that there is a range of consciousness (Navajas et al., 2014). It seems plausible that participants could stop processing a stimulus after determining that it was task-irrelevant without being fully conscious of it. For example, participants may be aware that a distractor stimulus is not a face, but still be unable to recognize or name it. Similarly, they could consciously perceive a face without being able to tell its identity, gender, or age. But even in these situations, participants must be conscious of some properties of those distractor faces (at least the properties that make distractor stimuli differ from target stimuli). In fact, they are able to recall those distractors after the task is finished, a phenomenon known as incidental memory (Castelhano and Henderson, 2005; Williams et al., 2005). Incidental memory of faces is an indicator that task-irrelevant stimuli can be consciously perceived in the absence of late EEG components (Kaunitz et al., 2014; Shafto and Pitts, 2015) and retrieved as episodic memories after the task.

One intriguing aspect of the evidence presented by Shafto and Pitts (2015) is that both early components (the N170 and the VAN) failed to show an all-ornone correlation with awareness. In fact, task-relevant faces elicited larger N170/ VAN components than task-irrelevant faces, even though in both conditions faces were consciously perceived. This is in clear conflict with proposals arguing that the all-or-none nature of consciousness (i.e., the idea that one can be aware or unaware that a given stimulus is a face, but not half-aware) should be reflected in an all-or-none NCC (Dehaene and Changeux, 2011). The authors' interpretation is that these early components might very well represent another cognitive process, e.g., visual attention. While this possibility cannot be ruled out because attention and awareness were not independently manipulated in Shafto and Pitts (2015) (for a review on the experimental manipulations used to manipulate awareness and attention, see Koch and Tsuchiya, 2007), an alternative interpretation could also explain their results. In the task-irrelevant condition, Shafto and Pitts (2015) assessed awareness by retrieving the subjective reports after the entire block of trials had concluded. With this experimental manipulation, the authors could establish that, overall, faces were consciously perceived in that set of trials. This assessment, however, cannot ensure that participants perceived all presented faces. As most attentional resources were deviated to a different task (thus yielding faces as taskirrelevant), it is reasonable to expect that faces were missed in some trials. This would lead to a smaller N170/VAN in the task-irrelevant condition as a consequence of averaging all trials: those that were consciously perceived and those that were not. Further research should aim to test this possibility to disambiguate the role played by the N170/VAN in eliciting conscious perception at the single-trial level (Navajas et al., 2013).

The most important theoretical implication of Shafto and Pitts (2015) is that distinguishing NCCs from the correlates of reporting one's perception can pose constraints on models of consciousness. The evidence provided by Shafto and Pitts (2015) favors the view that conscious face perception might arise earlier than $300 \mathrm{~ms}$ (Fisch et al., 2009; Navajas et al., 2013; Sandberg et al., 2013) and that the P3 component might correlate better with stimulus task relevance than with conscious perception. The quest to identify the spatiotemporal dynamics of consciousness in the brain is, however, still far from complete. In the future, it will be interesting to see if new versions of this paradigm can evaluate awareness on a trial-by-trial basis and, at the same time, disambiguate NCCs from other cognitive processes, such as attention.

\section{References}

Aru J, Bachmann T (2015) Still wanted-the mechanisms of consciousness! Front Psychol 6:5. CrossRef Medline

Aru J, Bachmann T, Singer W, Melloni L (2012) Distilling the neural correlates of consciousness. Neurosci Biobehav Rev 36:737-746. CrossRef Medline

Baars BJ (1988) A cognitive theory of consciousness. Cambridge: Cambridge UP.

Castelhano M, Henderson J (2005) Incidental visual memory of objects in scenes. Vis Cogn 12:1017-1040. CrossRef

de GraafTA, Hsieh PJ, Sack AT (2012) The 'correlates' in neural correlates of consciousness. Neurosci Biobehav Rev 36:191-197. CrossRef Medline

Dehaene S, Changeux JP (2011) Experimental and theoretical approaches to conscious processing. Neuron 70:200-227. CrossRef Medline

Dehaene S, Naccache L (2001) Towards a cognitive neuroscience of consciousness: basic evidence and a workspace framework. Cognition 79:1-37. CrossRef Medline

Dehaene S, Sergent C, Changeux JP (2003) A neuronal network model linking subjective reports and objective physiological data during conscious perception. Proc Nat Acad Sci U S A 100:8520-8525. CrossRef Medline

Fisch L, Privman E, Ramot M, Harel M, Nir Y, Kipervasser S, Andelman F, Neufeld MY, Kramer U, Fried I, Malach R (2009) Neural "ignition": enhanced activation linked to perceptual awareness in human ventral stream visual cortex. Neuron 64:562-574. CrossRef Medline

Kaunitz LN, Kamienkowski JE, Varatharajah A, Sigman M, Quiroga RQ, Ison MJ (2014) Looking for a face in the crowd: fixationrelated potentials in an eye-movement visual search task. Neuroimage 89:297-305. CrossRef Medline

Koch C (2004) The quest for consciousness. New York: Roberts and Co.

Koch C, Tsuchiya N (2007) Attention and consciousness: two distinct brain processes. Trends Cogn Sci 11:16-22. CrossRef Medline 
Koivisto M, Revonsuo A (2010) Event-related brain potential correlates of visual awareness. Neurosci Biobehav Rev 34:922-934. CrossRef Medline

Lamme VA (2000) Neural mechanisms of visual awareness: ALinking proposition. Brain Mind 1:385-406. CrossRef

Lamme VA (2003) Why visual attention and awareness are different. Trends Cogn Sci 7:12-18. CrossRef Medline

Navajas J, Ahmadi M, Quian Quiroga R (2013) Uncovering the mechanisms of conscious face perception: A single-trial study of the N170 responses. J Neurosci 33:1337-1343. CrossRef Medline

Navajas J, Rey HG, Quian Quiroga R (2014)
Perceptual and contextual awareness: methodological considerations in the search for the neural correlates of consciousness. Front Psychol 5:959. CrossRef Medline

Pitts MA, Martínez A, Hillyard SA (2012) Visual processing of contour patterns under conditions of inattentional blindness. J Cogn Neurosci 24:287-303. CrossRef Medline

Pitts MA, Metzler S, Hillyard SA (2014) Isolating neural correlates of conscious perception from neural correlates of reporting one's perception. Front Psychol 5:1078. CrossRef Medline

Sandberg K, Bahrami B, Kanai R, Barnes GR, Overgaard M, Rees G (2013) Early visual responses predict conscious face perception within and between subjects during binocular rivalry. J Cogn Neurosci 25:969-985. CrossRef Medline

Shafto JP, Pitts MA (2015) Neural signatures of conscious face perception in an inattentional blindness paradigm. J Neurosci 35:1094010948. CrossRef Medline

Sutton S, Braren M, Zubin J, John ER (1965) Evoked-potential correlates of stimulus uncertainty. Science 150:1187-1188. CrossRef Medline

Williams CC, Henderson JM, Zacks RT (2005) Incidental visual memory for targets and distractors in visual search. Percept Psychophys 67:816-827. CrossRef Medline 